\title{
Study on efficacy and prognostic indicators of sorafenib in advanced hepatocellular carcinoma
}

\author{
Yu Zhenyu ${ }^{1}$, ZhangJian ${ }^{1}$, Zhang Yingcai ${ }^{1}$, Liu Wei ${ }^{2}$, Yao Jia ${ }^{2}$, Tang Hui ${ }^{2}$, Li Haibo ${ }^{2}$, Wang Genshu ${ }^{2}$, Wang Guoying ${ }^{*}$, Yang Yang ${ }^{1,2}$ and Chen $^{2}$ \\ Guihua $^{1,2}$ \\ ${ }^{1}$ Department of Hepatic Surgery and Liver transplantation Center of the Third Affiliated Hospital, Organ Transplantation Institute, Sun Yat-sen University; Organ \\ Transplantation Research Center of Guangdong Province. Guangzhou 510630, China \\ ${ }^{2}$ Guangdong Key Laboratory of Liver Disease Research, the Third Affiliated Hospital of Sun Yat-sen University, Guangzhou 510630, China
}

\begin{abstract}
Objective: The aim of this study is to evaluate the efficacy of sorafenib monotherapy and investigate the potential prognostic indicators in patients with advanced hepatocellular carcinoma (HCC).

Methods: We retrospectively analyzed the clinical data of 143 advanced HCC patients received sorafenib treatment. The clinical data including alpha fetoprotein (AFP) before and after sorafenib treatment were recorded. We evaluated the status of the patients per 6 week. In the 12th week after sorafenib therapy, we evaluated the efficacy of sorafenib in advanced HCC by modified Response Evaluation Criteria in Solid Tumors (mRECIST). The primary endpoint was Time To Progress (TTP). The Log-Rank test was used to determine univariate prognostic indicators. The COX regression model was used to analyze the multivariate prognostic indicators.

Results: The median TTP was 4.0 months and the median overall survival time was 5.1 months. The Disease Control Rate of sorafenib in advanced HCC was $42 \%$. In univariate analysis, independent prognostic indicators include portal vein tumor thrombosis, Child-Pugh grade of liver function before sorafenib treatment, and early AFP reaction after sorafenib treatment. Child-Pugh grade of liver function (HR=0.409, 95\%CI: $0.193-0.867, \mathrm{P}=0.02)$ and early AFP reaction (HR=3.735, 95\%CI: $1.700-8.208, \mathrm{P}=0.01$ ) were two independent prognostic indicators.
\end{abstract}

Conclusion: Child-Pugh grade of liver function and early AFP reaction are potential prognostic indicators of sorafenib treatment in advanced HCC.

\section{Introduction}

The hepatocellular carcinoma (HCC) is one of the most common malignant neoplasm all around the world [1]. According to the data showed in cancer statistics in China, 2015, the mortality of HCC ranks in the third. HCC is the most common and the highest mortal malignant neoplasm in male within 60 years old [2]. Even thought there are several treatments of the HCC, the outcome of treatment is not satisfied, because of the delayed detection of HCC. Many patients lost the chance of radical treatment. Sorafenib is one of the standard treatments of the advanced HCC. As a multi-kinase inhibitor, sorafenib acts on both the signal system and vascular system of tumor cell [3]. Based on the two phase III randomized clinical trials (SHARP trial and Asia-Pacific trial) $[4,5]$, Sorafenib is therefore the recommended first-line treatment for patients with BCLC stage C HCC on the NCCN guideline since 2008 [6]. Despite the success of sorafenib for the treatment of advanced HCC, significant predictive factors for its effcacy are not available. The curative effect is not satisfied. The Disease Control Rate (DCR) of sorafenib in advanced HCC is less than 50\% [5,7]. It is necessary to find the potential prognosis indicators of sorafenib in HCC.

\section{Patients and methods}

\section{Study patients}

A total of 827 patients with HCC were treated with sorafenib between January 2009 and August 2016 at the Third Affiliated Hospital of Sun Yat-sen University, Guangzhou, China. Among them, 198 patients were excluded due to the following reasons: (1) loss to followup before the first assessment of response to sorafenib ( $n=76)$, (2) BCLC stage A or B $(n=52)$, (3) the Eastern Cooperative Oncology Group performance status (ECOG-PS) above 2 score $(n=70)$ [8]. Thereafter, we excluded 403 patients who were treated with combination therapies (radiofrequency ablation (RFA), transarterial chemoembolization (TACE), radiation therapy, systemic chemotherapy, other targeted agents, and metastasectomy). Thus, 226 patients were treated with sorafenib monotherapy. To evaluate the treatment outcome of sorafenib therapy, 83 patients who were treated with sorafenib for less than 8 weeks were additionally excluded due to the short duration of sorafenib administration. Finally, this study included 143 HCC patients who were treated with sorafenib monotherapy for at least 8 weeks. HCC was diagnosed on the basis of the clinical guidelines of hepatocellular carcinoma by Ministry of Public Health of China in 2011 [9].

Correspondence to: Wang Guoying, Department of Hepatic Surgery and Liver transplantation Center of the Third Affiliated Hospital, Organ Transplantation Institute, Sun Yat-sen University, Organ Transplantation Research Center of Guangdong Province. Guangzhou 510630, China; E-mail: wanggy3@126.com

Key words: hepatocellular carcinoma, sorafenib, efficacy, prognostic indicator

Received: November 20, 2017; Accepted: December 13, 2017; Published: December 16, 2017 


\section{Clinical parameters}

We reviewed the following clinical parameters: gender, age, ECOGPS, Child-Pugh classification, alpha-fetoprotein (AFP), early AFP reaction [10] which is defined as the AFP declines over 20\% compared with the baseline before treatment with sorafenib within 4 weeks [10], neutrocyte, lymphocyte, neutrocyte and lymphocyte ratio (NLR) [11], platelet, aspartate transaminase (AST), alanine transaminase (ALT), AST and ALT ratio, glutamyltranspeptidase (GGT), alkaline phosphatase (ALP), the characters of tumor which divided into massive hepatocellular carcinoma $(\geq 10 \mathrm{~cm})$, single nodular hepatocellular carcinoma $(<10 \mathrm{~cm})$ and multiple lesions of hepatocellular carcinoma, portal vein tumor thrombosis and distant metastasis.

\section{Sorafenib treatment}

In all patients, sorafenib treatment was initiated orally at a dose of $400 \mathrm{mg}$ twice daily, and the dose of the drug was modified in each patient as needed, according to the toxicity of the drug.

\section{Outcome measurement}

The response to sorafenib therapy and time to tumor progression were retrospectively investigated in HCC patients. The response to sorafenib therapy for advanced HCC was assessed on the basis of modified Response Evaluation Criteria in Solid Tumors (mRECIST) [12]. Disease control was defined when the tumor response was satisfactory in the form of complete remission (CR), partial remission (PR), or stable disease (SD) according to the mRECIST criteria. Time to tumor progression was regarded as a P20\% increase of the tumor thrombus in the greatest crosssectional diameter compared to a baseline tumor thrombus or occur new lesions [13]. Time to tumor progression was defined as the time from the start of sorafenib therapy to disease progression on imaging studies.

\section{Statistical analysis}

The efficacy of sorafenib and time to tumor progression was calculated by the Kaplan-Meier method. Univariable and multivariable Cox proportional hazards models were used to identify risk factors that predict the time to tumor progression after sorafenib administration. The variables for univariable analysis were selected on the basis of baseline characteristics of the enrolled patients: gender, age, ECOG-PS, Child-Pugh classification, alpha-fetoprotein (AFP), early AFP reaction, neutrocyte, lymphocyte, neutrocyte and lymphocyte ratio(NLR), platelet, aspartate transaminase (AST), alanine transaminase (ALT), AST/ALT ratio, glutamyltranspeptidase (GGT), alkaline phosphatase(ALP), the number of tumor which divided into massive hepatocellular carcinoma $(\geq 10 \mathrm{~cm})$, single nodular hepatocellular carcinoma $(<10 \mathrm{~cm})$, multiple lesions of hepatocellular carcinoma, portal vein tumor thrombosis and distant metastasis. The variables for the multivariable analysis were determined on the basis of their statistical significance in the univariable analysis $(p<0.20)$. The time to tumor progression according to the significant risk factors were compared using the Log-rank test. Statistical significance was achieved when the $\mathrm{p}$ value was less than 0.05 .

\section{Result}

\section{Baseline characteristics}

Table 1 presents the baseline characteristics of 143 enrolled patients with advanced HCC. One hundred and eighteen patients $(82.5 \%)$ were male. and one hundred and thirteen (79\%) less than 60 years old. Ninety-two patients were Child-pugh A class, while the others were Child-pugh B. Seventy-three patients (51\%) had ECOG performance
Table 1. Baseline characteristics of the patients $(\mathrm{N}=143)$

\begin{tabular}{|c|c|}
\hline & Number/mean \pm S.D. \\
\hline \multicolumn{2}{|l|}{ Gender(N,\%) } \\
\hline Male & $118(82.5 \%)$ \\
\hline Female & $25(17.5 \%)$ \\
\hline \multicolumn{2}{|l|}{ Age (years) } \\
\hline$\leq 60$ & $113(79 \%)$ \\
\hline$>60$ & $30(21 \%)$ \\
\hline \multicolumn{2}{|l|}{ Performance status } \\
\hline ECOG 0 & $73(51 \%)$ \\
\hline ECOG 1 & $70(49 \%)$ \\
\hline \multicolumn{2}{|l|}{ Child-pugh class (N,\%) } \\
\hline A & $92(64.3 \%)$ \\
\hline B & $51(35.7 \%)$ \\
\hline \multicolumn{2}{|l|}{$\operatorname{AFP}(\mathrm{ng} / \mathrm{ml})$} \\
\hline$\leq 25$ & $42(29.4 \%)$ \\
\hline$>25$ & $101(70.6 \%)$ \\
\hline \multicolumn{2}{|l|}{ Early AFP reaction } \\
\hline Yes & $80(55.9 \%)$ \\
\hline No & $63(44.1 \%)$ \\
\hline \multicolumn{2}{|l|}{ NLR } \\
\hline$\leq 2.81$ & $65(45.4 \%)$ \\
\hline$>2.81$ & $78(54.6 \%)$ \\
\hline \multicolumn{2}{|l|}{ PLT } \\
\hline$\leq 100$ & $74(51.8 \%)$ \\
\hline $100-300$ & $59(41.3 \%)$ \\
\hline$>300$ & $10(6.9 \%)$ \\
\hline \multicolumn{2}{|l|}{$\operatorname{AST}(U / L)$} \\
\hline$\leq 40$ & $65(45.4 \%)$ \\
\hline$>40$ & $78(54.6 \%)$ \\
\hline \multicolumn{2}{|l|}{$\operatorname{ALT}(\mathbf{U} / \mathbf{L})$} \\
\hline$\leq 35$ & $61(42.7 \%)$ \\
\hline$>35$ & $82(57.3 \%)$ \\
\hline \multicolumn{2}{|l|}{ AST/ALT } \\
\hline$\leq 0.91$ & $61(42.7 \%)$ \\
\hline $0.91-2.25$ & $56(39.2 \%)$ \\
\hline$>2.25$ & $26(18.1 \%)$ \\
\hline \multicolumn{2}{|l|}{ GGT(U/L) } \\
\hline$\leq 60$ & $69(48.2 \%)$ \\
\hline$>60$ & $74(51.8 \%)$ \\
\hline \multicolumn{2}{|l|}{$\operatorname{ALP}(\mathbf{U} / \mathbf{L})$} \\
\hline$\leq 125$ & $70(48.9 \%)$ \\
\hline$>125$ & $73(51.1 \%)$ \\
\hline \multicolumn{2}{|l|}{ Number of lesion } \\
\hline $\operatorname{Massive}(\geq 10 \mathrm{~cm})$ & $104(72.7 \%)$ \\
\hline Single lesion $(<10 \mathrm{~cm})$ & $12(8.4 \%)$ \\
\hline Multiple lesion & $27(18.9 \%)$ \\
\hline \multicolumn{2}{|l|}{ PVTT } \\
\hline Yes & $80(56.0 \%)$ \\
\hline No & $63(44.0 \%)$ \\
\hline \multicolumn{2}{|l|}{ Distant metastasis } \\
\hline Yes & $45(31.5 \%)$ \\
\hline No & $98(68.5 \%)$ \\
\hline
\end{tabular}

status 0 . One hundred and one patients (70.6\%) with a high level of AFP before sorafenib treatment. Besides, eighty patients (56\%) had PVTT while forty-five had a distant metastasis.

\section{Sorafenib administration and treatment interruption}

In all patients, sorafenib treatment was initiated orally at a dose of $400 \mathrm{mg}$ twice daily, and the dose of the drug was modified in each patient as needed, according to the toxicity of the drug. 


\section{Tumor response}

Tumor response to sorafenib was assessed in the first 12 week. None of the patients achieved CR, 16 patients (6.6\%) achieved PR, 86 patients (35.4\%) achieved SD, and 141 patients (58\%) achieved PD (Table 2). Disease control rate with sorafenib treatment was $42 \%$.

\section{Prognostic indicators for tumor progression}

The result of univariable and multivariable analysis of prognostic indicators for tumor progression after sorafenib therapy are shown in Table 3. In the univariable analysis, tumor progression was associated with performance status B $(\mathrm{P}=0.194)$, Child-pugh B liver function

Table 3. Prognostic indicators for tumor progression after sorafenib therapy in HCC patients

\begin{tabular}{|c|c|c|c|c|c|c|}
\hline & No. & $\begin{array}{c}\text { TTP } \\
\text { (month,median) }\end{array}$ & $\begin{array}{c}\text { TTP } \\
\text { (month, 95\%CI) }\end{array}$ & P value & \begin{tabular}{|} 
Multivariable HR (95\% \\
CI)
\end{tabular} & $P$ value \\
\hline \multicolumn{7}{|l|}{ Gender(N,\%) } \\
\hline Male & 118 & 3.3 & $2.523-4.077$ & & & \\
\hline Female & 25 & 4.2 & $3.616-4.784$ & 0.22 & & \\
\hline \multicolumn{7}{|l|}{ Age (years) } \\
\hline$\leq 60$ & 113 & 3.9 & $3.192-4.608$ & & & \\
\hline$>60$ & 30 & 4.1 & $3.983-4.217$ & 0.639 & & \\
\hline \multicolumn{7}{|l|}{ Performance status } \\
\hline ECOG 0 & 73 & 4.2 & $3.167-5.233$ & & & \\
\hline ECOG 1 & 70 & 3.3 & $2.580-4.020$ & 0.194 & $0.832(0.448-1.542)$ & 0.558 \\
\hline \multicolumn{7}{|l|}{ Child-pugh class } \\
\hline A & 92 & 4.1 & $3.481-4.719$ & & & \\
\hline $\mathrm{B}$ & 51 & 2.2 & $0.183-4.217$ & 0.013 & $0.409(0.193-0.867)$ & 0.02 \\
\hline \multicolumn{7}{|l|}{$\operatorname{AFP}(\mathbf{n g} / \mathbf{m l})$} \\
\hline$\leq 25$ & 42 & 4.1 & $0.979-7.221$ & & & \\
\hline$>25$ & 101 & 4.0 & $3.388-4.612$ & 0.208 & & \\
\hline \multicolumn{7}{|l|}{ Early AFP reaction } \\
\hline Yes & 80 & 5.0 & $3.677-6.323$ & & & \\
\hline No & 63 & 3.1 & $2.663-3.538$ & 0.001 & $3.735(1.700-8.208)$ & 0.01 \\
\hline \multicolumn{7}{|l|}{ NLR } \\
\hline$\leq 2.81$ & 65 & 5.0 & $3.784-6.216$ & & & \\
\hline$>2.0 .0281$ & 78 & 3.2 & $2.936-3.464$ & 0.38 & & \\
\hline \multicolumn{7}{|l|}{ PLT } \\
\hline$\leq 100$ & 74 & 3.3 & $2.321-4.279$ & & & \\
\hline $100-300$ & 59 & 4.2 & $3.314-5.266$ & & & \\
\hline$>300$ & 10 & 2.0 & $0.880-3.120$ & 0.001 & $1.27(0.029-0.560)$ & 0.22 \\
\hline \multicolumn{7}{|l|}{$\operatorname{AST}(\mathrm{U} / \mathrm{L})$} \\
\hline$\leq 40$ & 65 & 4.0 & $2.982-5.018$ & & & \\
\hline$>40$ & 78 & 3.9 & $2.628-5.172$ & 0.750 & & \\
\hline \multicolumn{7}{|l|}{$\operatorname{ALT}(\mathbf{U} / \mathbf{L})$} \\
\hline$\leq 35$ & 61 & 3.9 & $2.762-5.038$ & & & \\
\hline$>35$ & 82 & 4.0 & $3.102-4.898$ & 0.932 & & \\
\hline \multicolumn{7}{|l|}{ AST/ALT } \\
\hline$\leq 0.91$ & 61 & 3.1 & $2.662-3.538$ & & & \\
\hline $0.91-2.25$ & 56 & 4.0 & $3.859-4.141$ & & & \\
\hline$>2.25$ & 26 & 4.2 & $1.567-6.833$ & 0.534 & & \\
\hline \multicolumn{7}{|l|}{ GGT (U/L) } \\
\hline$\leq 60$ & 69 & 4.0 & $3.249-4.751$ & & & \\
\hline$>60$ & 74 & 3.0 & $1.272-4.728$ & 0.600 & & \\
\hline \multicolumn{7}{|l|}{$\operatorname{ALP}(\mathbf{U} / \mathbf{L})$} \\
\hline$\leq 125$ & 70 & 4 & $3.185-4.815$ & & & \\
\hline$>125$ & 73 & 3.2 & $2.000-4.400$ & 0.525 & & \\
\hline \multicolumn{7}{|l|}{ Number of lesion } \\
\hline Massive $(\geq 10 \mathrm{~cm})$ & 104 & 4 & $3.371-4.629$ & & & \\
\hline Single lesion $(<10 \mathrm{~cm})$ & 12 & 5.2 & $0.398-10.005$ & & & \\
\hline Multiple lesion & 27 & 3 & $0.211-5.789$ & 0.53 & & \\
\hline \multicolumn{7}{|l|}{ PVTT } \\
\hline Yes & 80 & 3 & $1.591-4.409$ & & & \\
\hline No & 63 & 4.2 & $3.000-5.400$ & 0.004 & $0.669(0.345-1.299)$ & 0.235 \\
\hline \multicolumn{7}{|l|}{ Distant metastasis } \\
\hline Yes & 45 & 4.1 & $2.047-6.153$ & & & \\
\hline No & 98 & 4.0 & $3.292-4.708$ & 0.47 & & \\
\hline
\end{tabular}


$(\mathrm{P}=0.013)$. early AFP reaction $(\mathrm{P}=0.001)$, PLT $>300^{\star} 10 \mathrm{e} 9(\mathrm{P}=0.001)$ and PVTT $(\mathrm{P}=0.004)$ (Figures 1,2$)$ The multivariable analysis showed the prognostic indicators for tumor progression were child-pugh class (HR 0.409, $\mathrm{P}=0.02$ ) and early AFP reaction (HR $3.735 \mathrm{P}=0.01$ )

\section{Discussion}

In this study, we investigated the efficacy of sorafenib therapy in advanced HCC patients, and the prognostic indicator for tumor progression. At the 12 week after sorafenib therapy, we assessed the tumor response. The disease control rate with sorafenib was $42 \%$. It means that even treated with sorafenib systematically, there will be over half of patients suffer from disease progression. Thus it is necessary to figure out the diagnostic indicators to guide our therapy so as to raise the efficiency of sorafenib therapy. Among the clinical materials, we figure out that the ECOG-PS, liver function Child-pugh class, early AFP reaction, PLT and PVTT may be the potential prognostic indicators for sorafenib therapy. Through multivariable analysis, we found that the liver function child-pugh class and early AFP reaction are predictive indicator for sorafenib therapy with advanced HCC patients. This study suggests us that during the treatment of advanced HCC patients with sorafenib, we should try to improve the liver function. monitoring the AFP during treatment is another way to assess the efficacy of sorafenib on certain patient.

These result could be useful in determination of clinical treatment strategies for patients with advanced HCC. Further studies are needed to confirm the diagnostic indicator of sorafenib in advanced hepatocellular carcinoma.

\section{Funding sources}

This work was supported by grants from National Natural Science Foundation of China $(81370575,81470870,81370555,81372243)$, the

Table 2. Tumor response to sorafenib therapy.

\begin{tabular}{|c|c|}
\hline Tumor response & N.(\%) \\
\hline Complete response & $0(0 \%)$ \\
\hline Partial response & $16(6.6 \%)$ \\
\hline Stable disease & $86(35.4 \%)$ \\
\hline Progressive disease & $141(58 \%)$ \\
\hline Disease control (+) & $102(42 \%)$ \\
\hline Disease control (-) & $141(58 \%)$ \\
\hline
\end{tabular}

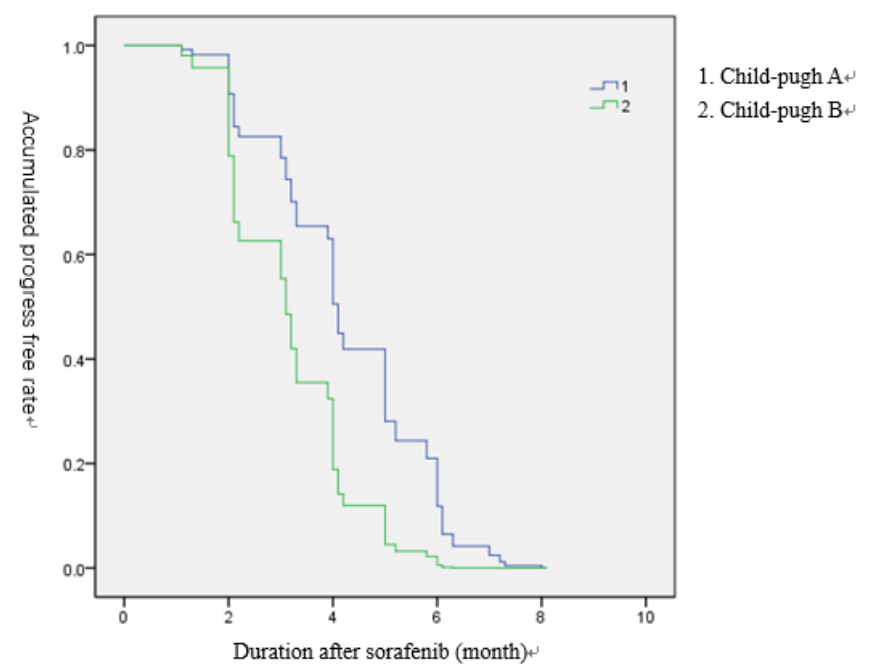

Figure 1. Duration of Sorafenib accumulation progress free rate in child-pugh.

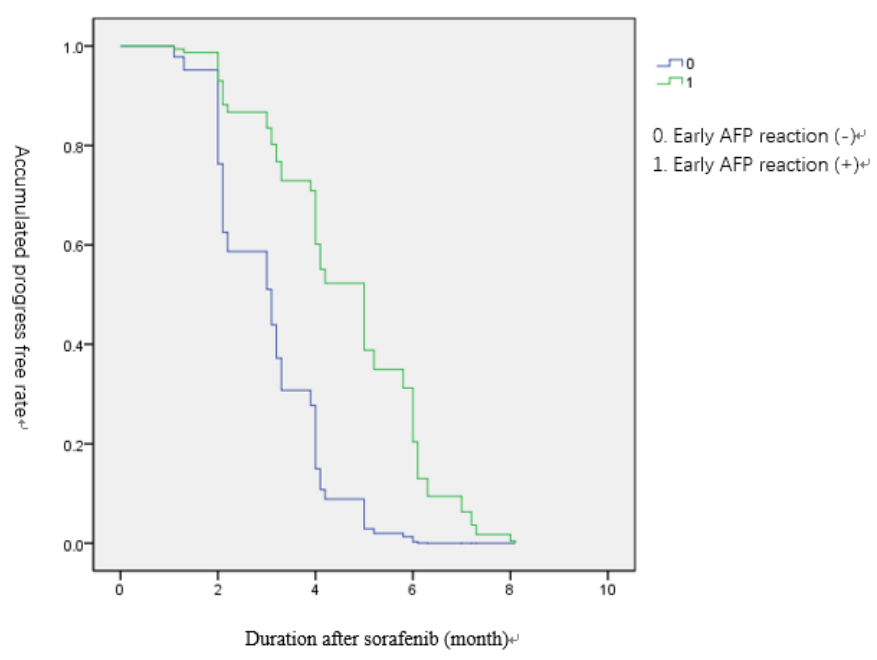

Figure 2. Duration of Sorafenib accumulation progress free rate in early alpha fetoprotein (AFP).

Natural Science Foundation of Guangdong Province (2015A030313038, 2015A030312013), the Science and Technology Program of Guangdong Province (2014A020211015, 2014A020212575).

\section{References}

1. El-Serag HB (2011) Hepatocellular carcinoma. N Engl J Med 365: 1118-1127. [Crossref]

2. Chen W, Zheng R, Baade PD, Zhang S, Zeng H, et al. (2016) Cancer statistics in China, 2015. CA Cancer J Clin 66: 115-132. [Crossref]

3. Wilhelm S, Carter C, Lynch M, Lowinger T, Dumas J, et al. (2006) Discovery and development of sorafenib: a multikinase inhibitor for treating cancer. Nat Rev Drug Discov 5: 835-844. [Crossref]

4. Llovet JM, Ricci S, Mazzaferro V, Hilgard P, Gane E, et al. (2008) Sorafenib in advanced hepatocellular carcinoma. $N$ Engl J Med 359: 378-390. [Crossref]

5. Cheng AL, Kang YK, Chen Z, Tsao CJ, Qin S, et al. (2009) Efficacy and safety of sorafenib in patients in the Asia-Pacific region with advanced hepatocellular carcinoma: a phase III randomised, double-blind, placebo-controlled trial. Lancet Oncol 10: 25-34. [Crossref]

6. NCCN (2008) The NCCN hepatobiliary cancers Clinical Practice Guidelines in Oncology.

7. Llovet JM, Ricci S, Mazzaferro V, Hilgard P, Gane E, et al. (2008) Sorafenib in advanced hepatocellular carcinoma. $N$ Engl J Med 359: 378-390. [Crossref]

8. Oken MM, Creech RH, Tormey DC, Horton J, Davis TE, et al. (1982) Toxicity and response criteria of the Eastern Cooperative Oncology Group. Am J Clin Oncol 5: 649655. [Crossref]

9. Mengchao $\mathrm{Wu}$, Zhaoqiu Tang (2011). Clinical guidelines of hepatocellular carcinoma Chinese Clinical Oncology 16: 929-946.

10. Shao YY, Lin ZZ, Hsu C, Shen YC, Hsu CH, et al. (2010) Early alpha-fetoprotein response predicts treatment efficacy of antiangiogenic systemic therapy in patients with advanced hepatocellular carcinoma. Cancer 116: 4590-4596. [Crossref]

11. Okamura Y, Ashida R, Ito T, Sugiura T, Mori K et al. (2015) Preoperative Neutrophil to Lymphocyte Ratio and Prognostic Nutritional Index Predict Overall Survival After Hapatectomy for Hepatocellular carcinoma. World J Surg 39: 1501-1509. [Crossref]

12. Eisenhauer EA, Therasse P, Bogaerts J, Schwartz LH, Sargent D, et al. (2009) New response evaluation criteria in solid tumours: revised RECIST guideline (version 1.1) Eur J Cancer 45: 228-247. [Crossref]

13. Llovet JM, Di Bisceglie AM, Bruix J, Kramer BS, Lencioni R, et al. (2008) Design and endpoints of clinical trials in hepatocellular carcinoma. J Natl Cancer Inst 100 698-711. [Crossref]

Copyright: (C2017 Zhenyu Y. This is an open-access article distributed under the terms of the Creative Commons Attribution License, which permits unrestricted use, distribution, and reproduction in any medium, provided the original author and source are credited. 